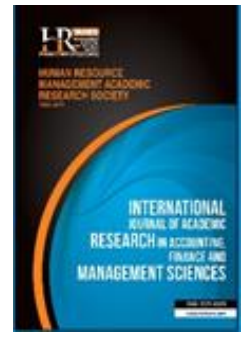

International Journal of Academic Research in Accounting, Finance and Management Sciences

Vol. 8, No.4, October 2018, pp.30-38

E-ISSN: 2225-8329, P-ISSN: 2308-0337

(c) 2018 HRMARS

www.hrmars.com

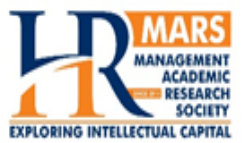

To cite this article: Gitau, G.G., Kiragu, D.N., Kamau, R. (2018). Effect of Heuristic Factors and Real Estate Investment in Embu County, Kenya, International Journal of Academic Research in Accounting, Finance and Management Sciences 8 (4): 30-38.

\title{
Effect of Heuristic Factors and Real Estate Investment in Embu County, Kenya
}

\author{
Geoffrey Gikonyo GITAU ${ }^{1}$, David N. KIRAGU², Riro KAMAU ${ }^{3}$ \\ 1,2,3 Dedan Kimathi University of Technology, E-mail: futurefocusc@gmail.com
}

\begin{abstract}
Investment decisions are deemed as a deliberate and rational process based on availability of information. Though at times people are usually found to hold little information but yet end up making general decisions. Heuristics factors are simple rules of the thumb which explain how people make decisions, arrive at judgments and solve problems when faced with complex situations or in cases where the available information is incomplete. This study sought at assessing the influence of the heuristic factors on real estate investment in Embu County. The study was guided by Heuristic Theory. A census of 126 registered real estate investors from Embu town, Runyenjes and Siakago Urban centers was undertaken. Primary data was collected through a selfadministered questionnaire composed of closed ended questions. Cronbach alpha coefficient of 0.7 was used to ascertain test of the reliability of the data collection instrument. Descriptive and regression analysis were used to analyze data with the help of statistical package. Inferential statistics was also carried out to establish the nature of the relationship that exists between heuristic factors and real estate investment. Data was interpreted with the help of 0.05 significance P-values. Model fitness $R^{2}$, ANOVA statistics and regression coefficient were generated. Prior to running a regression model, normality test was conducted. The study findings indicated heuristics factors have a positive and statistically significant relationship with real estate investment in Embu County. This study concludes that real estate investors in Embu County sometimes do not make investment decisions rationally but are influenced by heuristic biased decisions. The study recommends that Embu County Government should establish a mechanism to ensure that the prices of real estate in specific regions are availed to enable investors evaluate price changes as it may influence their decision to buy or sell the investment.
\end{abstract}

Key words

Heuristics factors, real estate investment

Received: 30 Nov $2018 \quad$ (c) The Authors 2018

Revised: 15 Dec 2018 Published by Human Resource Management Academic Research Society (www.hrmars.com)

Accepted: 52 Dec 2018 This article is published under the Creative Commons Attribution (CC BY 4.0) license. Anyone may reproduce, distribute, translate and create derivative works of this article (for both commercial and noncommercial purposes), subject to full attribution to the original publication and authors. The full terms of this license may be seen at: http://creativecommons.org/licences/by/4.0/legalcode

\section{Introduction}

\subsection{Background to the Study}

Kahneman (2011) described heuristics factors as simple rules of the thumb which explain how people make decisions, arrive at judgments and solve problems when faced with complex situations or in cases where the available information is incomplete. He noted that ppeople are usually found to hold little information and make general decisions, but, yet end up making a correct decision. According to Shah and Oppenheimer (2008), these "mental short cuts" that ease the burden of decision making are referred to as heuristic factors. Heuristics reduce decision making work in numerous ways; by the ability to scrutinize few signals and alternative choices in decision making; reducing the information retrieval and storage work; streamlining the process of making decision for ease of choice or passing judgment. 
People usually rely on host of heuristics. Most important heuristic factors include representative, availability, gambler's fallacy, overconfidence, anchoring and judgment. First, representative heuristic which occurs when one chooses a thing due to its recognizability hence utilizing the least effort or information to make decisions (Hilbi and Pohl, 2008). Simply making a conclusion due to event A resembling event $\mathrm{B}$. The second important heuristic factor is availability which is when one makes a decision since the information available can be retrieved easily (Redelmeier, 2005).

The third heuristic is anchoring and judgment which the foundational decision is making heuristic where some estimate of value is needed (Epley and Gilovich, 2006). This is mostly seen when in negotiation table; people tend to make a counter offer depending on the anchoring provided to them. People tend to start with a first value, then followed by some adjustment leading to the final answer. Fourth, overconfidence heuristic is manifested when an individual chooses to invest in only one alternative fully they are familiar with, even if there exist more rationally justifiable alternatives (Jordan and Miller, 2008). For example, an investor may invest in debt instrument of one local company rather than for an international company since the investor may be unfamiliar with it Dietrich (2010).

According to Ruitha (2010), there has been rapid growth in demand for residential and commercial premises in Kenya calling for expansion in the real estate sector. The explosion of the population has been experienced in cities and towns due to urbanization. Ruitha noted that the supply of housing is well below the plans. Kenya's blueprint for development Vision 2030 estimated the 200,000 housing units per annum, while of today only 35,000 are being built per annum. Real estates have not yet established proper regulation system. Real estate developer and agents are people in-charge of operating and/or managing the real estate market. However, with the introduction of Real Estate Investment Trusts (REITS) in the Capital Market Authority (CMA) will enhance trade of real estates in Nairobi Securities Exchange.

The study sought to examine the relationship between heuristic factors and real estate investment in Embu County with a population of 267,609 being male and 275,615 being females resulting to a total population of 543,221 and 131, 683 numbers of households (County Government of Embu, 2013). This population is estimated to be growing at an annual rate of $1.7 \%$. Wanzala (2013) noted that land has been seen appreciating rapidly in Embu Town as a result of population growth and upsurge in demand for rental housing.

\subsection{Problem Statement}

Investment in real estate has been on the upsurge in Kenya mostly in towns and now clustered in Counties in the current legal systems of County Government. Real estate contributes over $7 \%$ to Gross Domestic Product (GDP) directly and therefore one of the key Sectors in Kenya. This sector is therefore key in the achievement of $10 \%$ growth rate as envisioned in Kenya's development plan to 2030 and beyond. By 2016, Embu was reported as one of the key Counties in Kenya, with a fast growing need for housing and rising number of investors in real estate, residential and largely commercial houses attracting over five international investors in the last three years (2015-2018). Viability of real estate project implies that investments must be done in a fairly rational manner in the evaluation of the investment risks, timing and amount of cash flows. If this is not done with caution, these investments could lead to wealth erosion rather than the expected wealth creation, against the planned investment objectives, limiting employment and Sustainable Development Goal (SDG 5) on fostering economic growth and industrialization. The heuristic factors and real estate investment has scarcely been studied. Besides, none of the prior study known to the researcher has been conducted in Embu County. This study is therefore set out to assess the influence of heuristic factors on real estate investment in Embu County.

\subsection{Research Objective}

The objective of the study was to assess the influence of heuristic factors on real estate investment in Embu County.

\subsection{Significance of the Study}

This study could help investment advisors and the financial institutions discover what really guides investors when it comes to making investment decisions. Heuristic factors play an undeniable role in 
influencing individuals' decisions, including investment decisions. Findings from this research would equip investment advisors and financial institutions with more informed quality advice to investors not only from theory but also empirical studies. This study will add to the growing body of knowledge in the field of real estate investments and can therefore be used later as reference for future studies.

\section{Literature review}

\subsection{Heuristic Theory}

"Heuristics are simple efficient rules of thumb which have been proposed to explain how people make decisions, come to judgement and solve problems, typically when facing complex problems or incomplete information. These rules work well under most circumstances, but in certain cases lead to systematic cognitive biases"-Daniel Kahneman (Parikh, 2011). Heuristics are defined as the rule of thumb, which makes decision making easier, especially in complex and uncertain environment (Ritter, 2003). Waweru et al. (2008) explains that in general heuristics are quite useful particularly when time is limited. Shah and Oppenheimer (2008) suggest that although current theories of heuristic processing do suggest that people simplify how they make judgement and decisions these theories rarely explain how these processes reduce the amount of effort required.

\subsection{Heuristic Factors and Real Estate Investment}

Heuristics factors are factors that applies rule of thumb to simplify a complex problem or decisions that need to be made in unlikely environments (Ritter, 2003) by forecasting simpler judgments using probabilities and especially under limitations of time circumstances (Waweru et al., 2008; Loung and Ha, 2011). Robin (2002) explains heuristics by use of "law of small numbers," which is the belief that small sample or branches can be a representative of the parent population. Skinner (2004) study of the Indian Stock Market found that there is a difference between behaviour patterns of investors. This study was based on the influence of certain identified behavioural finance concepts or biases, on the decision making process of individual investors who were categorized into two groups of young and experienced.

The results of the study found that, "Gamblers Fallacy, Anchoring and Hindsight biases affected the young investors significantly more than experienced investors." By applying the behavioural finance theory, Mwangi (2011) studied how behavioural factors influence Kenyan property market investment decisions. One hundred and fifty five listed real estate agents in Nairobi region were selected for the survey from the yellow pages. The results of the findings indicated that there were two classifications of human cognitive illusions: heuristic and prospect theory. More specifically, the author found that heuristics theory comprised of anchoring, representativeness and availability bias had greater impact on the investment decisions making.

Osmond, Adebayo and Adesiyan (2013) investigated the valuation of property investment as result of using of heuristics factors in Nigeria. The key heuristic factors considered by the study were availability, representative, anchoring, adjustment and positivity. A total of two hundred and eighteen (218) Estate Surveying and Valuation Firms in three cities were select randomly for cross sectional administration of questionnaires. These primary data were measured using ordinal scale. Osmond et al. confirmed that the four heuristics factors actually influenced property values in the study areas. However, this study should have tested the nature of the relationship between the heuristics factors and valuation of estate property.

Lowies and Hall (2015) examined whether anchoring and adjustment as heuristic - driven bias influences listed property fund managers in South Africa property investment decisions. Seventeen questionnaires were sent via email to listed property fund managers operating in Johannesburg Securities Exchange. A survey based design was used. The results from the non-parametric tests showed that the fund managers anchored information on favourable property even if the new information showed the original anchor to be less favourable. These results were consistent to findings of past studies (Leung \& Tsang, 2013; Bucchianeri and Minson, 2013). Results also found no statistical ground for property fund managers to exhibit herding behaviour. Scott and Lizieri (2012) investigated the anchoring effect on UK house price valuations through an incentivized experiment on students. Scott and Lizieri argued that the student sample represents first time home buyers. It was established that valuation judgments of house prices were anchored to arbitrary values. Bucchianeri and Minson (2013) too studied the relationship 
between anchoring and pricing strategies of houses. The authors found signs of anchoring and insufficient adjustment to correlate positively with higher listing prices.

\subsection{Conceptual Framework}

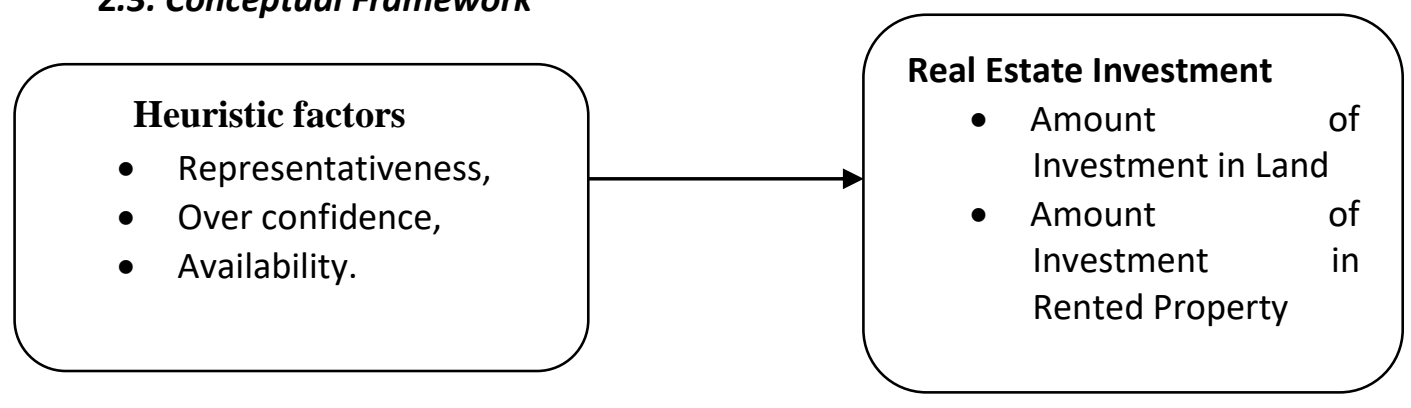

Figure 1. Conceptual Framework

\subsection{Research Gaps}

Kenya is seemed to be one Country that is recently laying emphasis in real estate development. Few studies have been conducted to research on heuristic factor especially in real estate investment in Africa and Kenya in particular. The real estate investments are highly and densely located in main Cities in Kenya and it might be important to explore the scenario with emergence of County Governments especially in Embu County which creates a contextual gap. More rapid growth and development based on the county locations has face lifted the regions and calling for more and more development in real estate at the county level to cater for the explosion in population modernization and urbanization.

\section{Methodology of research}

\subsection{Research Design}

The study adopted descriptive research design. According to Oso and Onen (2009) a descriptive survey design seeks to describe the situation as it is. It's appropriate in the current study since the study sought to explain the relationship between heuristic factors and real estate investment in Embu County. A census of 126 registered real estate investors from Embu town, Runyenjes and Siakago Urban centers was undertaken. Primary data was collected through a self-administered questionnaire composed of closed ended questions. Saunders (2007) supports the use of closed ended questions since they are easily answered since minimal writing is required. The choice of closed ended questions increases completeness on questions responses.

\subsection{Test of Reliability}

Kombo and Tromp (2006) argued that reliability of the research instrument is attested through its ability to yield similar results if administered to different respondents. Cronbach alpha coefficient of 0.7 was used to ascertain test of the reliability of the data collection instrument. The results of the reliability of this study gave the alpha value of 0.727 as shown in table 1 which implies that data collection instrument was reliable and fit for the purposes of the study since the Cronbach alpha coefficient exceeding 0.70 .

Table 1. Reliability Test Results

\begin{tabular}{ccc}
\hline Variables & Number of Items & Cronbach's Alpha Coefficient \\
\hline Heuristic Factors & 6 & .727 \\
\hline
\end{tabular}

\subsection{Data Analysis and Presentation of Results}

The collected data was cleaned and edited to ensure completeness and consistency. The data was then analysed using descriptive and inferential statistics with the help of statistical package for social sciences. Inferential statistics was carried out to establish the nature of the relationship that exists between heuristic factors and real estate investment. Data was interpreted with the help of 0.05 significance Pvalues. Model fitness $\mathrm{R}^{2}$, ANOVA statistics and regression coefficient were generated. Prior to running a regression model, normality test were conducted. 
The linear regression equation for this study was in the form;

$Y=\beta_{0}+\beta_{1} X_{1}+\varepsilon$

$Y=$ Real Estate Investment decision

$X_{1}$. Heuristic factors

$\varepsilon$ - Error term

In the model, $\beta_{0}$ is the constant term; the coefficient $\beta_{i}$ is used to measure the sensitivity of the dependent variable $(Y)$ to unit change in the predictor variables while $\varepsilon$ is the error term which captures the unexplained variations in the model.

\section{Findings and discussions}

\subsection{Response Rate}

The study targeted the targeted one hundred and twenty six (126) registered real estate investors in Embu County. Out of the 126 questionnaires that were issued, 118 were dully filled and returned to the researcher for analysis. This gave a response rate of $93.7 \%$ which is considered as very good according to (Mugenda and Mugenda, 2004).

\subsection{Investment Experience of Respondents}

Investment experience of respondents in the Embu County was sought to establish whether the respondent were fairly familiar with the behavioural factors that could affect real estate investment in Embu County.

Table 2. Distribution of Respondents by Investment Experience

\begin{tabular}{ccc}
\hline Investing Experience of Respondents & Frequency & Percent \\
\hline Less than Five & 19 & 16.1 \\
6 to 10 Years & 31 & 26.3 \\
11 to 15 Years & 12 & 10.2 \\
16- 20 Years & 24 & 20.3 \\
Over 20 Years & 32 & 27.1 \\
Total & $\mathbf{1 1 8}$ & $\mathbf{1 0 0 . 0}$ \\
\hline
\end{tabular}

From the Table 2, 16.1\% of the respondents have invested in Embu County for less than 5 years, $26.3 \%$ of the respondents have invested for period between $6-10$ years, $10.2 \%$ have invested for $11-15$ years, and $20.3 \%$ have invested for $16-20$ years while $27.1 \%$ have invested for more than 20 years. Thus majority of the persons who responded had invested in Embu County for more than 6 years. In this case, given that more than $83 \%$ of the total respondents had more than 6 years investment experience in Embu County, it is expected that the respondents had in-depth information regarding the behavioural factors that affects real estate investment in Embu County.

\subsection{Age of the Respondents}

Information of interest in this study was the age of the respondents. This study thus sought to establish the age category of the respondents. It was more desirable to have a reasonable representation of all study age categories. Respondents were asked to indicate the age categories that they belonged to in a five age categories of below 20 years, between 21 - 30 years, between $31-40$ years, between $41-50$ years and over 50 years of age. The results are presented in Figure 2.

From Figure 2, the results indicate that $0.85 \%$ of the respondents were below 20 years, $19.5 \%$ were aged between $21-30$ years, $27.1 \%$ were aged between $31-40$ years, $35.6 \%$ between $41-50$ years whereas $16.9 \%$ of the respondents were 50 years and above. Thus most of the respondents were in aged between 31-50 years. These results presented a practical scenario where only an insignificant percentage of employees below the age of 20 years would be expected to be in working category and that a majority of the employees would be above 20 years of age. The results also show that majority of the respondents (62\%) were of over 41 years of age. It might be reasonable to assume that majority of the respondents in this age group would be expected to have reasonable experience in investment in the real estate. 


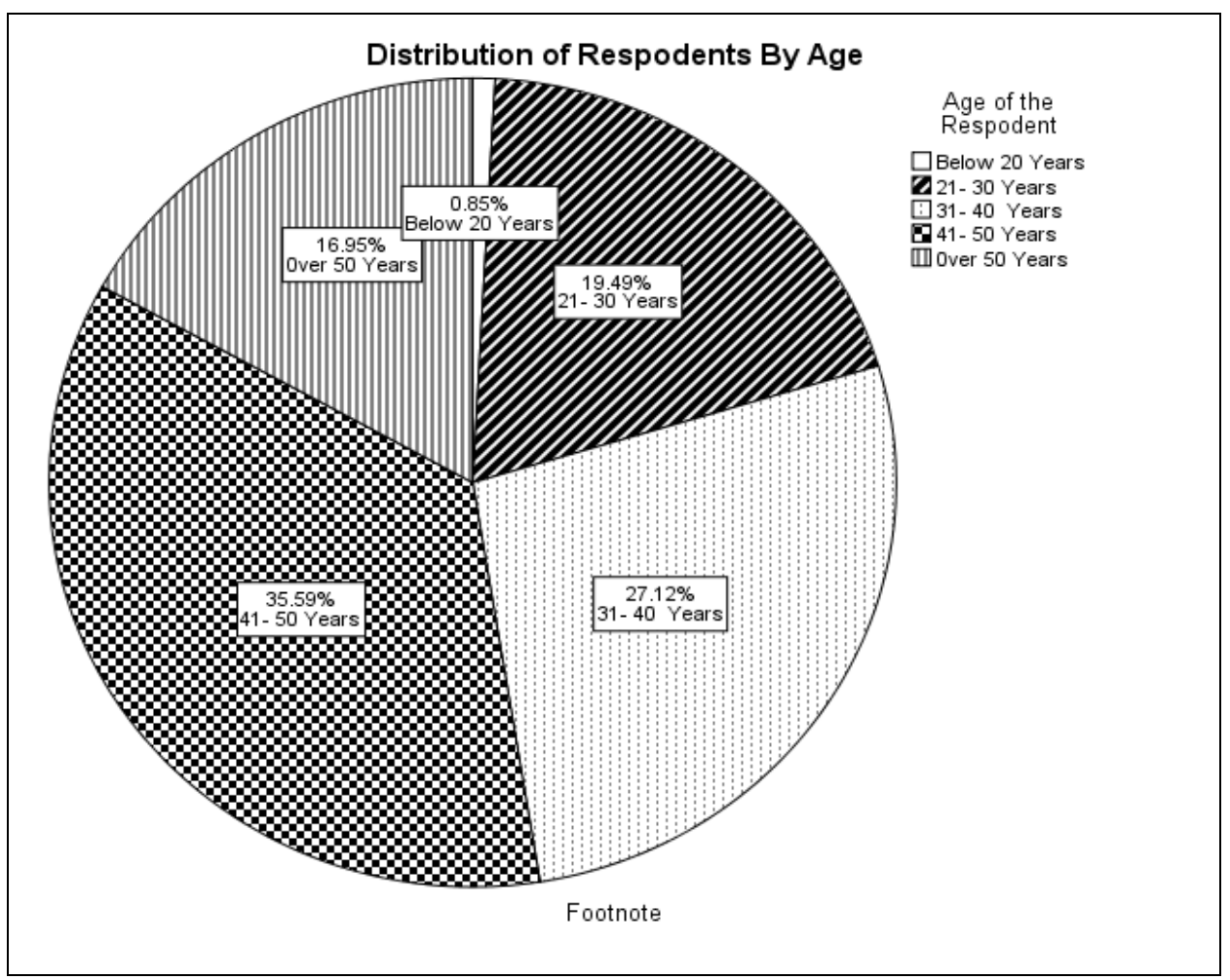

Figure 2. Distribution of Respondents by Age Category

\subsection{Normality Test on the Dependent Variable}

To test for normality of the regression analysis, the study employed the graphical method for normality. The results from the graphical method are presented in the Figure 3 below, indicating that the residuals are normally distributed.

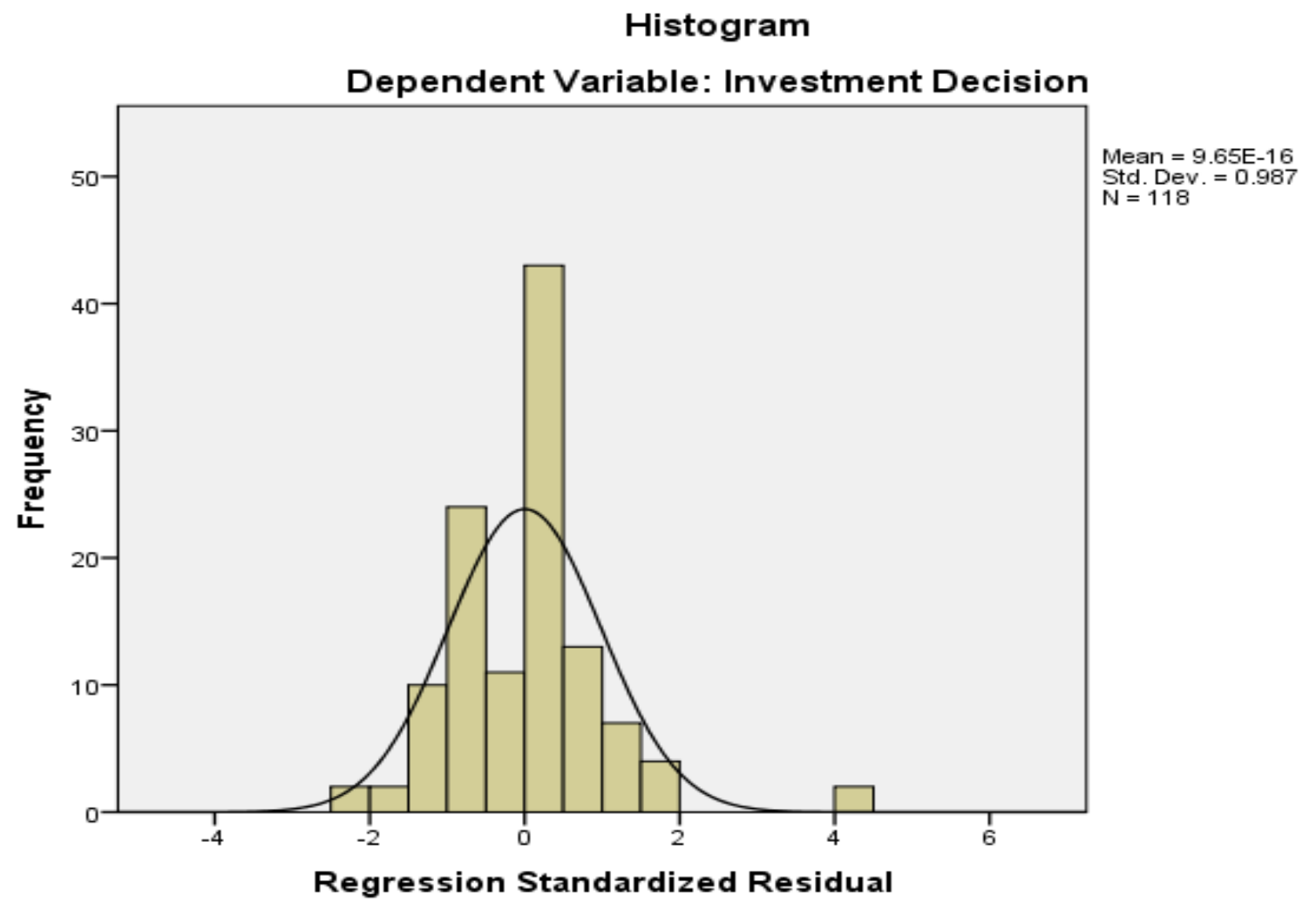

Figure 3. Histogram of the Real Estate Investment 


\subsection{Heuristic Factors and Real Estate Investment decisions}

A heuristic is a mental shortcut that allows people to solve problems and make judgments quickly and efficiently. These rule-of-thumb strategies shorten decision-making time and allow people to function without constantly stopping to think about their next course of action (Barberis, 2001). It is on this premise, the first objective of the study sought to assess the effect of heuristic factor on investors' decision making to invest in real estate.

Table 3. Descriptive analysis of Heuristic Factors

\begin{tabular}{lcccc}
\hline \multicolumn{1}{c}{ Heuristic Factors } & N & Mean & Std. Error & Std. Deviation \\
\hline Pricing of RE based on recent Selling/ Buying Price & 118 & 4.09 & .079 & .857 \\
Use of Trend Analysis & 118 & 4.06 & .087 & .945 \\
Use of past Experience to predict Future & 118 & 4.03 & .089 & .965 \\
Have High expectations on Return beyond market Expectations & 118 & 3.91 & .092 & 1.004 \\
Use of RE Buy price to determine point of selling/Trading & 118 & 3.87 & .086 & .930 \\
Predictive Skills to time and outdo the Market & 118 & 3.80 & .077 & .833 \\
Valid N (listwise) & 118 & & & \\
\hline
\end{tabular}

Pricing of real estate based on recent selling/buying price was highly rated with mean of 4.09 followed by use of trend analysis with a mean of 4.06. Use of past experience to predict future had a mean of 4.03, high expectations on return beyond market expectations had a mean of 3.91.

Use of real estate buy price to determine point of selling/trading had a mean of 3.87 while predictive skills to time and outdo the market had a mean of 3.80. This means that investors mainly focus on the recently sold parcel of land to establish the price but they also analyse the trend of the real estate when making investment decisions. Overall, it is evident from the above evaluation that investors consider heuristic factor under consideration when making real estate investment decisions.

Table 3. Model Summary for Heuristic Factors

\begin{tabular}{ccccc}
\hline Model & $\mathbf{R}$ & $\mathbf{R}$ Square & Adjusted R Square & Std. Error of the Estimate \\
\hline 1 & $.247^{\mathrm{a}}$ & .061 & .053 & .939 \\
\hline
\end{tabular}

a. Predictors: (Constant), Heuristic Factors

From the regression results in Table 4.2, the $R$ value was 0.247 indicating that there is a relationship between heuristic factors on real estate investment decisions in Embu County. The $R$ squared $\left(R^{2}\right)$ value of 0.061 shows that approximately 6.1 percent of the real estate investment decisions are explained by heuristic factors. The remaining 93.9 percent is explained by other factors. In order to assess the significance of the influence of heuristic factors on real estate investment in Embu County, ANOVA Statistics were generated. The results are presented in Table 4.

Table 4. ANOVA for Heuristic Factors

\begin{tabular}{llccccc}
\hline & Model & Sum of Squares & df & Mean Square & F & Sig. \\
\hline \multirow{2}{*}{1} & Regression & 86.670 & 1 & 6.670 & 7.567 & $.007^{\mathrm{b}}$ \\
& Residual & 22.254 & 116 & .881 & & \\
& Total & 108.924 & 117 & & & \\
\hline
\end{tabular}

a. Dependent Variable: Real estate investment decision

b. Predictors: (Constant), Heuristic Factors

Table 4 shows an $F$ ratio of 7.567 and an associated $p$ value 0.007 which is less that $p=0.05$. These values are an indication that heuristic factors when considered singly have a statistically significant influence on real estate investment decisions in Embu County. These results agree to Shah and Oppenheimer( 2008) who suggest that there is a relationship between investment and heuristics and that it is possible that investors at times apply simple rules that seem to work for them instead of applying complex models in decision making.

Similarly these findings agree to those of Lowies and Hall (2015) who tested the same factors in South African listed property Market. In addition, these findings are similarly to those of Osmond, Adebayo 
and Adesiyan in Nigerian property investment. Apart from establishing an existing relationship, these results confirm a statistically significant influence of heuristic factors on real estate investment. While most of the studies in behavioural finance are conducted in developed economics and organised security markets, this study appears to indicate that in an emerging economy like Kenya, behavioural investors largely use the same decision making rules as is the case in developed security markets.

Table 5. Regression Coefficients for Heuristic Factors

\begin{tabular}{|c|c|c|c|c|c|c|}
\hline & \multirow{2}{*}{ Model } & \multicolumn{2}{|c|}{ Unstandardized Coefficients } & \multirow{2}{*}{$\begin{array}{c}\text { Standardized Coefficients } \\
\text { Beta }\end{array}$} & \multirow{2}{*}{$\mathbf{T}$} & \multirow{2}{*}{ Sig. } \\
\hline & & B & Std. Error & & & \\
\hline \multirow{2}{*}{1} & (Constant) & 3.233 & .301 & & 10.753 & .000 \\
\hline & Heuristic Factors & .215 & .078 & .247 & 2.751 & .007 \\
\hline
\end{tabular}

a. Dependent Variable: Real estate investment decision

Heuristic factors had positive and significant effect on real estate investment decisions. With $\beta=$ 0.215 at $p$ value 0.007 which is less than 0.05 . The indication was that as the heuristic factors are enhanced by one unit, a real estate investment decision is enhanced by 0.215 . The bivariate regression equation for this study can be stated as: $Y=3.233+0.215 \mathrm{X}_{1}+$ e. where $\mathrm{X}_{1}=$ heuristic factors. This is an indication that heuristic factors considered in this study greatly influences investors decision to invest in real estate.

\section{Conclusions and Recommendations}

The study sought to examine the effect of heuristics factors on real estate investment decision in Embu County. Based on the findings the study concludes that heuristics factors positively and significant effect on investors' decision making of real estate investment at $5 \%$ level of significance. The study further revealed that majority of the respondent base the pricing of real estate on recent selling/ buying price where the investors in real estate over react to price changes of investment by either buying or selling depending on their future projections. In addition, most of the respondents concurred that investors use of trend analysis of price changes based on past experience and expectations of return to make real estate investment decisions. Following these findings, this study recommends that Embu County establish mechanism to ensure that the prices of real estate in specific regions are made available to enable investors evaluate price change as it influence their decision to buy or sell the investment. In addition the study recommends that investors need to evaluate heuristic factors before making real estate investment decision.

\section{Future researches}

The study confined itself to the effect of heuristic factors on real estate investment in Embu County while there is need to undertake comparative studies covering real estate investment in other Counties in order to validate whether the findings can be generalized. Future researchers should also focus on challenges investors face while making real estate investment decisions. A study could also be undertaken to evaluate the effect of other factors which could affect real estate investment rather than heuristic factors considered in this study.

\section{References}

1. Bucchianeri, G.W. and Minson, J.A.(2013), "A homeowner's anchoring in residential dilemma: anchoring in residential real estate transactions", Journal of Economic Behaviour \& Organization, Vol.89, No.1, pp. 76-92.

2. Dietrich, C. (2010). "Decision Making: Factors that Influence Decision Making, Heuristics Used, and Decision Outcomes." Student Pulse, 2(02). Retrieved from http://www.studentpulse.com/a?id=180

3. Epley, N., \& Gilovich, T. (2006). The anchoring-and-adjustment heuristic. Psychological Science, 17(4), 311-318. DOI: 10.1111/j.1467-9280.2006.01704.x

4. Hilbig, B.E., \& Pohl, R.F. (2008). Recognition users of the recognition heuristic. Experimental Psychology, 55(6), 394-401. DOI: 10.1027/1618-3169.55.6.394.

5. Jordan, B., \& Miller, T. (2008). Fundamentals of Investments. McGraw-Hill. 
6. Kahneman, D. (2011). Thinking, Fast and Slow. New York: Macmillan.

7. Kombo, D. K., \& Tromp, D. L. (2006) Proposal and Thesis Writing: An Introduction. Paulines Publications Africa. Nairobi.

8. Leung, T.C. and Tsang, K.P. (2013), "Anchoring and loss aversion in the housing market: implications on price dynamics", China Economic Review, Vol. 24, No.1, pp. 42-45.

9. Lowies, G.A., Hall, J. H, and Cloete, C.E .(2015)," The role of market fundamentals versus market sentiment in property investment decision-making in South Africa," Journal of Real Estate Literature, Vol.23 No.2, pp.297-314.

10.Mugenda, O. M., \& Mugenda, A. G. (2009) Research Methods: Quantitative and Qualitative approaches. Nairobi Africa Centre for Technology Studies (ACTS) press. Nairobi.

11.Mwangi, G.G, (2011) Behavioural Factors Influencing Investment Decisions in the Kenyan Property Market. Unpublished Master of Commerce (Mcom) Project, Strathmore University Nairobi, Kenya.

12.Osmond, I. C., Adebayo, O. O., Adesiyan, O. S., \& Moronke O. M., (2013). Factors Affecting the Usage of Major Heuristics in Nigeria Property Investment Valuation. Journal of Sustainable Development Studies. 4(2), 114-133.

13.Oso W.K. \& Onen D (2009). A guide to writing research proposal and report. A handbook for beginning researchers. Revised Edition. Jomo Kenyatta Foundation.

14.Parikh, P. (2011). Value Investing and Behavioural Finance. New Delhi: Tata Mcgraw Hill.

15.Phouc Luong, L. and Thi Thu Ha, D. (2011), "Behavioural Factors influencing individual investors'decision-making and performance: a Survey at the Ho Chi Minh Stock Exchange (Master Dissertation)", UMEA University Sweden

16.Rabin M (2002). Inference by Believers in the Law of Small Numbers. The Quarterly Journal of Economics. 117(3):775-816.

17.Redelmeier, D.A. (2005). The cognitive psychology of missed diagnosis. Annals of Internal Medicine, 142(2), 115-120.

18.Ritter, J.R. (2003), "Behavioral finance", Pasific-Basin Finance Journal. Vol.11, No.4 pp. 429-437

19.Ruitha, J. (2010), Emerging opportunities in the housing industry in Kenya. The National Housing Corporation.

20.Saunders, M., Lewis, P. and Thornhill, A. (2007). Research Methods for Business Students, $4^{\text {th }}$ Edition, Financial Times Prentice Hall, Edinburgh Gate, Harlow.

21.Scott, P.J. and Lizieri, C. (2012). Consumer house price judgements: new evidence of anchoring and arbitrary coherence, Journal of Property Research, Vol. 29 No.1, pp.49-68.

22.Shah, A.K., \& Oppenheimer, D.M. (2008). A framework for understanding how strategies for saving effort underlie numerous heuristics.

23.Shah, A.K., Oppenheimer, D.M. (2008). Heuristics Made Essay: An Effort-Reduction Framework, Psychological Bulletin Vol.134, No.2, 207-222.

24.Skinner, B.F. (2004). Science and human behavior. Cambridge: Sinner Foundation Publisher.

25.Wanzala, W. (2013). Quest for quality and relevant higher education, training and learning in Kenya: an overview. Education Journal 2013; Vol. 2 No. 2, pp. 36- 49, pp. 36-49. Published online: http://www.sciencepublishinggroup.com/j/ edu) doi: retrieved March 2, 20.

26.Waweru, N.M., Munyoki, E. (2008). The effects of behavioural factors in investment decisionmaking: a Survey of Institutional investors operating at Nairobi Stock Exchange. International Journal of Business and Emerging Markets 1(1), 24-71.

27.Zikmund, W. G., Babin, B. J., Carr, J. C., \& Griffith, M. (2010). Business Research Methods (8th edit.). Canada, South-Western Cengage. 